\title{
The Thinking of Practice Course of Urban and Rural Planning Administration: Combining the Lectures with the Interviews
}

\author{
Fan Yang, Juelin Shen* \\ College of Architecture and Urban Planning, Tongji University, Shanghai, China.
}

How to cite this paper: Fan Yang, Juelin Shen. (2020). The Thinking of Practice Course of Urban and Rural Planning Administration: Combining the Lectures with the Interviews. The Educational Review, USA, 4(5), 113-119.

DOI: $10.26855 /$ er.2020.05.002

Received: April 26, 2020

Accepted: May 20, 2020

Published: May 26, 2020

Corresponding author: Juelin Shen, College of Architecture and Urban Planning, Tongji University, Shanghai, China.

Email: kiwi.s1j213@163.com

\begin{abstract}
This paper introduces the Course Setting of Planning Administration Practice of urban-rural planning major in Tongji University. The teaching organization mode combined the in-class lectures and the interviews in the administrative department, which got unexpected harvest and brought a great deal of inspiration. On the one hand, the in-service officials with extensive planning and management experience brought students a lot of information and experience not accessible in class. On the other hand, students could understand the important position of planning administration in planning process. This paper points out that educational reform of urban planning should pay attention to the trend of professional needs and management system transformation, and continue the discipline spirit as well. Furthermore, while passing on idealism to students, the teachers should emphasize the important significance of solving practical problem in parallel.
\end{abstract}

\section{Keywords}

Urban planning administration, Practice course, Planning practice, Reform in education

\section{Background}

The course of Urban-Rural Planning Administration Practice of urban-rural planning major in Tongji University for undergraduates is a practice course with a short history in lack of relevant teaching accumulation. The working experience in planning administration and urban administration helps the author to master and organize the course; the author tries to present more truths of urban-rural practice to students. However, there are some challenges in specific teaching arrangement. For instance, as required by school system, the undergraduates in this year must finish both graduate design and planning administration practice in the same semester. Comprehensively from time and energy distribution, learning interest and completion of teaching task, the students will face difficulties in planning administration practice (Yang, 2013). When the author is writing this seminar paper, planning administration practice is still in progress. Nonetheless, this course is a new course worthy of attention.

\section{Purpose of the Course}


Setting this practice course for undergraduates is a very important exploration, a signal and an advanced teaching behavior. It can be described in one sentence that is "what the course is determines the understanding of a subject". (It can be described in one sentence as "the content of the course determines the understanding of a subject"). There is still a concept called "30\% planning and 70\% administration" (Zhou, 1998; Zeng, 2012) which can reflect the inner reason why the college sets up this course. In fact, at least in author's opinion, planning administration is not a continuation of urban-rural planning, but a part of it.

The purpose of this practice course is to give students more comprehensive understanding on urban-rural planning and teach them to review knowledge and skills acquired from planning administration. This process is difficult to complete by lecturing on urban-rural planning administration and law courses alone. It needs planning administration practice which, in other words, is a necessary complement to urban-rural planning management and laws from the perspective of local learning and an important content in "planning recognition" besides "urban recognition" from the perspective of planning education.

\section{Information from Practice}

Planning administration practice is finally carried out in a "lecture+ survey" manner. Wherein, the lecture is completed by inviting the principal of Shanghai Planning and Land Resources Bureau to give a lecture; the survey is completed by arranging students to make interview and survey in the planning administration departments. And then, the students are required to integrate the collected information based on the predesigned survey orientation. At present, both parts have gained surprising effects and based on several significant pieces of information, analysis is carried out as follows:

\subsection{External Information Brought by Introduced Lectures}

\section{1) The Reform of Site Plan Approval System}

The principal of Planning Bureau mentioned in the lecture that "site plan" would not be exclusively approved any more. Traditionally, Planning Bureau grants the "Land Use Permit" based on the planned site plan and relevant drawings, i.e., site plan contents, in the management process of issuing "Permission Notes for Location", "Land Use Permit" and "Building Permit", which are called "one document and two certificates" in Chinese. Since the regulatory plan has gradually become a vital basis and means for planning administration in recent years and in site plan there are many uncertainties, manmade factors and flexibility of modification, the site plan has gradually been inconsistent with the planning administration targeted at justice, fairness, and reducing lease space and personal preferences.

Such planning administration reform not only happens in Shanghai. According to the information gained by the author from planning practice, almost all urban planning administrative departments in China abolished the conventional site plan approval 2-3 years ago and issue the "Land Use Permit" according to the architectural design review guided by regulatory plan. The truth that site plan is long gone in essence brings quite a shock to students.

\section{2) The Critical Thinking on "Two Plans as One” and Urban Development Boundary}

The lecture on "two plans as one", which means the combination of the comprehensive planning and the general land use planning, and urban development boundary brought striking attention of students. Firstly, the difficulty of "two plans as one" lies in coordinating the administrative objectives of different departments, not in technology. Secondly, due to the relationship between related administrative laws the plans based on, it's more accurate to call the "coherence" of the comprehensive planning and the general land use planning instead of the "combination". 
Thirdly, while adapting to the scale of urban construction, the urban development boundary cannot be just right but be flexible which is reflected in both time span and space selection.

Senior undergraduates might be short of corresponding knowledge, especially the knowledge gained from practice, to understand the contents of the lecture, but they are highly enthusiastic in the lecture with common thinking and asking, which represents that senior students tend to focus more on hot spots, especially those which are affecting the scientific development orientation of urban planning as well as their orientation in major and career choices. At the same time, we must realize that the key to understanding such questions lies in interests rather than knowledge.

\section{3) The Other Considerations on Always Tearing Down Historical Buildings}

When talking about the means and key points of the management of areas with historical cultural features, the principal of Planning Bureau put forward a systematic administrative mechanism, which is the integration of urban design, regulatory plan and the protection of areas with historical cultural features. In fact, the protection of historical cultural features is a relatively critical subject in domestic urban construction. On the one hand, the students do not understand what the governments and administrative departments do; on the other hand, they commonly think developers are to blame.

The principal in the Administration of Laws and Regulations of Planning Bureau then revealed that the government cannot make a difference in the areas with historical cultural features due to the complicated interest conflicts and social livelihood issues which are caused by the special features among residents in historical buildings and contemporary history. Once the government has to act, these buildings cannot be preserved according to the relevant demolition and resettlement regulations. Such information is far beyond what students have learned in class and brings them thinking.

\subsection{The Vital Gain from the Interviews in the Administrative Department}

The students investigated and surveyed the issues, which were designed the general orientations before class, in groups based on interest. The subjects of issues can be generally divided into two major directions, one is "the role of planning administration in the process of industrial land redevelopment and reuse", the other is "the function of planning administrative technical regulations on the formation of urban space”. The students eventually found that many planning realities gained through the interviews and surveys in the administrative departments are different from what they learned in class, which made them intrigued.

1) The Issue on Industrial Land Reuse Reflects the Irrelevance Between Planning Administration and Planning Design

The students found Shanghai had tried a lot on industrial land re-development and reuse through the interviews and field surveys. Although Shanghai has put in place a set of relatively complete industrial land regeneration policies, there is still a need for specific treatment of specific cases in terms of implementation and management. For instance, Shanghai has explored the transformation of some of industrial parks outside the central city into "talent apartments" or "land for R\&D headquarters" to realize the reuse of industrial land. Both groups of the students have found that reasonable planning design are faced with the influence of laws, administrative system, social and economic demands, space justice and other complicated factors during the implementation. Planning cannot be realized by only a good thought or idea, but by consensus and balance in all aspects and in line with the requirements of the legal and regulatory systems as well.

\section{2) Land Use Management and Building Use Management Are the Keys to Planning Administration}

The industrial land in city center, different from the conditions above, is mainly transformed into areas with 
innovative industry agglomeration or comprehensive office due to better location. This kind of industrial land reuse has many cases with mature means and policies supported by government. However, the students still found many facts previously unknown through the administration practice. For instance, many industrial lands transformed into innovative industrial parks suffer nonconformance between planned land property and certificate. Interest disputes caused by ownership and lease term lead to difficult implementation of planning. The groups investigating the transformation of industrial buildings into office found that the transformation of industrial space would be eventually blocked by institutional factors if only relying on design innovation, because there the legal definition and administrative mechanisms for building property and financial market assessment are rigid. For another example, the land property and building approval details eventually determine the possibility of the mixed use of space in the process of compound updating towards original land use; that is to say, the micro administrative system makes the ideal descriptions of function mixture at the macro level, which are heard in the planning courses, totally impossible.

3) Space Shaping is not the Result of Control Prescribed by the Planning Administrative Technical Regulations

As for recent hot spots like "planning control of urban design", several groups of the students participated in the investigation of the correlations between Shanghai Municipal Planning Administrative Technical Regulations and regulatory planning and urban design in space administration. They realized that generation of urban space is more dependent on the space planning related to regulatory planning and urban design, but less on the planning administrative technical regulations. This is because planning administration based on "technical regulations", focusing more on the considerations of engineering technology, safety, health, efficiency and so on, is the agreement and restraints of "bottom line" and has an influence on the space shaping objectively, which means that the generation of urban space is not the original purpose of planning administrative technical regulations.

\section{Enlightenment}

"How urban-rural planning education can cope with the need of the profession and the reform of the administrative system?” is a question the author has been thinking about.

\subsection{Rethinking of Urban-rural Planning Education}

The original teaching content is a result of long-term accumulation, not overnight (Wu \&Yang, 2019). Moreover, in the view of the relative stability of education, it cannot be adjusted too frequently and drastically to meet the needs of the job market and the reform of the system. Urban-rural planning education is a personalized education based on individual cognition and therefore pays more attention on individual growth (Zhong, 2018; Wu \& Gan, 2019).

\section{1) Think Twice before Cancelling or Enhancing a Teaching Content}

The adjustment of teaching content to meet the requirements of planning occupation and practice is necessary (Lv, 2015). However, it is not just to cancel or add a certain course, but to carry out the necessary reform of teaching objectives, methods and preference based on the current curriculum system; that is to say, we should improve the training of students in all aspects by extending or deepening the course.

Taking the example of the reform of the site plan, the local planning administrations have strengthened the review and approval of the regulatory plan and construction drawings instead of the site plan to improve the administrative efficiency, although the methods for urban plan formulation and rules for the implementation have not been modified so far. Meanwhile, "land requisition planning", one original function of the site plan, now is gradually undertaken by the regulatory plan. Furthermore, over-large modification space after site plan approval will not only increase the 
difficulties and costs of administration, but also bring the risk of questioning the solemnity of approval. As a result, almost all local planning administrations have stopped conducting the review and approval of the site plan results. However, it is apparently overreacted if we think that the course of planning design in class is not necessary any more. On the contrary, the fact, gained from the principal in the Administration of Laws and Regulations of Planning Bureau, is that the shaping of urban space depends more on the regulatory plan and urban design, but not the administrative technical regulations, which are only the bottom lines of engineering technology. Therefore, the design ability obtained from the site plan is still vital in the process of shaping the urban space.

It should not discard the course of spatial design simply due to the change of administrative systems or occupation demands, because this course has always been critical to cultivate students' ability of spatial thinking. The key to the course reform is how to guide the students to transform the spatial language into spatial policy language more actively after the cultivation of the abilities of spatial thinking and judgement and remind them not to overlook that spatial planning is the real existence oriented to implementation, users and city governors when shaping the space.

\section{2) Emphasize Ability Development with Knowledge Indoctrination}

The lecture part of the planning administration practice shows that the contents brought by the invited lecturers, different from the teachers in class are more popular among the students and get higher recognition. It implies that the reform is too little with too old information and even has the possibility of being divorced from reality. The long-term focus and emphasis on knowledge indoctrination will lead to the fixed mind-set, which is bad for motivating students' interest. Meanwhile, it also overlooks the students' ability to understand and accept to some extent, which is obviously not suitable for the characteristics of students in the internet and information age.

The interview part of the planning administration practice also stimulates the students to think in a different way. What the students have learned in class is usually about basic tool for criteria and theory for "what the world should be", but practice makes the students try to find out "what the world is supposed to be". Taking the cause behind frequent demolition of historic buildings as an example, the real situation often befuddles the students because it is beyond the simplest reasoning which the teachers repetitively talk about. And this situation is difficult to radically change if the students only learn to be angry instead of seeking solutions which, however, are not learnt from books. The lectures and interviews make the students understand that the demolition of historic buildings is the result of the combination of various factors, like living conditions, social attributes and historical causes of those who live in these buildings as well as their decision on whether retain the historic buildings or not, which cannot be gained in class.

Many groups of the students realized that planning administration and system are indispensable links between planning design and built environment, through the administration practice. This truth will not be much empathy for the students if they learn from the theory courses, even if they write down on notes, but will be a shock if they experience in practice and find out that how complicated the administrative process of a plan is, from a planner to final establishment. "Planning is a public policy with space attributes" can be commonly said and heard, but can be only understood by those who go through it. Such practice experience will definitely influence students' spatial design, urge them to achieve effective, reasonable and legal distribution of space and meet requirements for the implementation regulations in their designs so that to realize the distribution of spatial value.

\subsection{Special Course for Special Person}

Planning education requires to focus not only on quality education, but also on skill education, which, or, are interpenetrating and complementing each other. Planning administration practice stimulates the author to think that to what degree we are conducting the quality education and skill education on students respectively, which requires a review on skill developing in planning education. 
Our course setting is often in extremes, employment-oriented or against it, or balancing employment orientation with pure idealism, which is another typical compromising attitude. The author cannot tell which attitude is correct or appropriate, but at least these attitudes can bring us thought and debate so that to reach the consensus, which is more important. And, a kind of subtle reform may come into being, as a straw shows which way the wind blows. So, we need to hear more opinions, especially those different, the external voice and what the students think.

The course shapes the person. The course setting is determined by the long-term accumulated understanding towards the profession among teaching groups, but not formed in the twinkling of an eye. The planning administration practice is directly correlated to urban-rural planning administration and regulation theories. The author has several thoughts on the education process through organizing the practice. Firstly, reduce unrealistic contents. Since urban-rural planning is not a major like physics or chemistry, just making experiments in doors, it must confront realistic issues and teach the students the tools for solution. Meanwhile, the teachers cannot lecture "ostrich" thinking, complacent with self-improvement and appreciation. Secondly, establish reality-oriented judgment criterion. The graduates of urban-rural planning major are faced with practical demands, so they have to raise sounder countermeasures while not relinquishing ideal and romanticism. At the same time, the teachers should avoid establishing the criterion for good and bad based on the personal idealistic factors and encourage the students to establish the criterion by their own understanding and practice (Yang, 2012). Thirdly, the teachers cannot just teach the students to be "angry skillfully”. Since there are still many legal, institutional and mundane laws to abide by in social mechanisms, urban-rural planning is not a profession to overcome all and the planning principle is not the only common criterion. The teachers should calmly acknowledge the limitation of this major instead of avoiding issues and those cannot be settled.

\section{Conclusion and Prospect}

The teaching accumulations for planning administration practice are in great shortage. However, through the teaching organization work of this semester in 2015, the author and the cooperative teachers adopt the teaching method combining the lectures with the interviews, which cannot be accounted as planning administration practice in a full sense but still achieved an unexpected harvest. The most valuable harvest is that the students grew more interest and raised intriguing questions, indicating that the practice has reached certain effect.

Planning administration practice is a good channel for the communication between school teaching and urban management demand, providing a new perspective for students to improve their abilities and understand what they have learned, and exerting a great positive influence on the cultivation of the students' planning knowledge and ability in other aspects. It is also a course in which we try to open a window for undergraduates of urban-rural planning major to observe the city, understand and participate in urban social and economic activities before their graduation.

\section{Funding}

Project of Teaching Material Construction for Graduate Students, 2020, Tongji University (Number: 2020JC02).

\section{References}

Lv, B. (2015). Planning Education Should Meet the Needs of Career Development. City Planning Review, 39(01), 95-97.

Wu, Z. Q., \& Yang, T. (2019). Early Development of Urban Planning Education in Tongji University. Urban Planning Forum, 03, 11-19. doi: 10.16361/j.upf.201903001.

Wu, Z. Q., \& Gan, J. (2019). Current Status and Future Direction of Graduate Course Development for Urban and Rural Planning Program in China. Academic Degrees \& Graduate Education, 01, 41-45. doi: 10.16750/j.adge.2019.01.008.

Yang, F. (2012). Let Students Tell Us. Humanistic Planning, Creative Transformation: Proceedings of National Steering Committee 
of Urban Planning Education in China 2012. Beijing: China Architecture \& Building Press.

Yang, F. (2013). Classroom Case Teaching Method for Urban and Rural Planning Administration and Laws. Beautiful City and Country, Sustainable Planning: Proceedings of National Steering Committee of Urban Planning Education in China 2013. Beijing: China Architecture \& Building Press.

Zhou, J. J. (1998). “Planning Taking Thirty Percent and Management Seventy Percent” Existing Urban Planning Management in China during the Transition and the Consideration about the Reforms. City Planning Review, 05, 10-13+59.

Zeng, Y. (2012). Thirty Percent Compilation and Seventy Percent Administration: Urban-Rural Integration Planning of Chengdu. City Planning Review, 36(01), 80-85+91.

Zhong, S. (2018). Theories and Practice of Research-Centered Teaching in Urban-Rural Planning Pedagogy. Urban Planning Forum, 01, 107-113. doi: 10.16361/j.upf.201801013. 